\title{
A leitura oral na escola do mundo contemporâmeo: uma prática marginal ou inexistente?
}

\section{Adriana Cunha de Oliveira UFMG}

Este trabalho investigou se a leitura em voz alta ou oral é uma prática marginal ou inexistente nos primeiros anos de escolarização do Ensino Fundamental em duas escolas municipais de Belo Horizonte. Para tanto, os professores, sujeitos da pesquisa, foram submetidos a um pequeno teste, em que, em um quadro, deveriam relacionar como trabalhavam a leitura em sala de aula. Os resultados evidenciaram, pois, que a leitura em voz alta ou oral é uma prática frequiente nos primeiros anos de escolarização. Contrariamente ao que se pensava, revelaram que essa prática é o "carro-chefe" do trabalho dos professores com leitura em sala de aula, pelo menos, até a $4^{a}$ série. Em vista dos resultados, relacionamos e discutimos algumas hipóteses que pudessem justificá-los, assim como analisamos a concepção de leitura que permeia a prática de leitura dos docentes nas duas escolas investigadas.

This study investigates whether reading aloud or oral reading is either an off stream or a nonexistent practice in the first years of the primary school in two municipal schools of Belo Horizonte. In order to do that, the teachers, participants of this research, were asked to do a little test: they had to list on a table how they used to teach reading in class. The results showed that reading aloud or oral reading is a frequent practice in the first years of school. Contrary to what we had thought, it was revealed that this practice is the mainstream of reading teaching in class, at least, until the fourth grade. Considering the results, we listed and discussed some hypothesis that could justify the results, and also we analyzed the concept of reading underlying the reading teaching of the participants of the two investigated schools. 


\section{Introdução}

No mundo contemporâneo, temos sido testemunhas de falácias consensuais de que a leitura oral, hoje, não é uma prática da escola, tampouco, dos diversos setores da sociedade. Ao contrário disso, a leitura silenciosa é tida, pois, pela sociedade atual, como uma prática por excelência. Autores famosos também ratificam, explicitamente, ou, às vezes, sutilmente, o imperialismo da leitura silenciosa no mundo contemporâneo, o que, também, pode contribuir para fomentar a crença na cultura do silêncio, além, é claro, dos guias de leitura ${ }^{15}$, que, a partir do século XIX, foram tão disseminados no mundo ocidental. Esses guias evidenciam as vantagens da leitura silenciosa, tais como a economia de tempo e do esforço visual, o auxílio na compreensão, a liberdade de escolha, a maior velocidade de leitura.

Cavallo e Chartier (1998), por exemplo, tratam a leitura oral como uma prática que, atualmente, se não é marginalizada, desapareceu. Sua função é não só a comunicação escrita aos não leitores, como a viabilização da sociabilidade.

Da mesma forma, Barbosa (1991), apesar de tratar a leitura silenciosa como uma prática, que, gradativamente, impõe-se nos séculos IX, X e XI no interior dos mosteiros; no século XIII, no mundo universitário e, durante a metade do século XIV, na aristocracia laica, refere-se a uma revolução silenciosa, a partir da invenção da imprensa em 1444, que instaura uma nova modalidade de relação com o texto, mais ágil, flexível e eficaz, consolidando uma nova forma de ler exclusivamente visual. Já esse autor considera que a leitura silenciosa suplantou a leitura oral, embora isso tenha ocorrido paulatinamente. Mas seria a invenção da imprensa a responsável por uma transformação nas práticas de leitura, como afirma Barbosa (1991)? O que também pode ter motivado uma nova relação do leitor com o texto? Terá mesmo a prática de leitura oral desaparecido ou ficado à margem, restrita a um pequeno grupo no mundo contemporâneo?

Para tratarmos dessas questões, lembramos Cavallo e Chartier (1998: 26-27), que apontam alguns fatores motivadores das mudanças nas práticas de leitura:

\footnotetext{
Ver PENNELL, CUSACK. Como se ensina a leitura. s.d., p. 92-93.
} 
Em primeiro lugar, é claro que em suas estruturas essenciais, o livro não é transformado pela nova técnica. Até o início do século XVI, pelo menos, o livro impresso ainda depende do manuscrito do qual imita a paginação, a escrita, as aparências. Como o manuscrito, ele deve ser acabado pela intervenção de várias mãos (...). (Em segundo lugar), (...) o livro, tanto depois como antes de Gutemberg, é um objeto semelhante, composto por folhas dobradas, reunidas em cadernos e juntadas sob uma mesma encadernação ou capa. Portanto, não é surpreendente que todos os sistemas de referência (numeração de folhas, de colunas e linhas; relação analítica entre o texto e suas glosas, $e$ não só espacial; índices; listas alfabéticas; concordâncias), que com muita rapidez foram associados à imprensa lhe sejam amplamente anteriores (...). (Outra razão é que) (...) já nos últimos séculos do livro copiado à mão, é organizada uma hierarquia durável dos formatos que distingue o grande fólio, o libro da banco, (...); o livro humanista, mais maleável em seu formato médio, que traz a leitura de textos clássicos e de novidades; enfim, o libellus, o livro portátil, de bolso ou de cabeceira, com múltiplas utilizações, para leitores numerosos e com menos dinheiro.

Esses autores sustentam, também, que, assim como na Antiguiidade grega e romana coexistiam as duas maneiras de ler (em silêncio e em voz alta), há, também, testemunhos de que, na Idade Média, houve práticas monásticas de leitura em voz alta em igrejas, refeitórios comunitários e até nas escolas.

Finalmente, esses autores defendem, ainda, que a revolução da leitura deve-se, fundamentalmente, à transformação na função do escrito do que à invenção da imprensa. Até o século XII e XIII, a escrita, cuja 
função era ser memorizada e conservada, segue um modelo monástico, que é substituído pelo escolástico. Já esse modelo de escrita, contrariamente, possibilita uma leitura mais ágil e interior, de forma que o livro seja tanto objeto como instrumento do trabalho intelectual.

Ressaltamos, também, que o suporte tem uma grande responsabilidade na produção do sentido e na relação do leitor com o texto, pois "(...) é preciso considerar que as formas produzem sentido e que um texto se reveste de uma significação e de um estatuto inéditos quando mudam os suportes que o propõem à leitura" (Cavallo e Chartier, 1998: 6).

Assim, com certeza, podemos salientar que a mudança no tipo de suporte-do rolo para o códex-, séculos antes da invenção da imprensa, foi outro fator responsável pela transformação da prática de leitura oral para uma prática silenciosa. Ao afirmarmos isso, estamos concordando com esses autores sobre a supremacia da leitura oral na Antigüidade e Idade Média e da leitura silenciosa a partir da Idade Moderna, mas, mais uma vez, lembramos que essas práticas, em vários momentos, coexistiram. Da mesma forma, a leitura intensiva de pequenos corpus de livros religiosos e sagrados, que eram lidos, memorizados, recitados e passados de geração a geração, parece ter coexistido com a leitura extensiva, caracterizada por ser uma leitura livre, desenvolta e irreverente, marcada pelo consumo excessivo de textos. Logo, para Cavallo e Chartier (1998) e para nós, a revolução do livro é ulterior à da leitura, cuja prática silenciosa é bem anterior à metade do século $\mathrm{XV}$, quando houve a invenção da imprensa.

Da mesma forma, Manguel (1999) e Saenger (1989) consideram que a prática de leitura silenciosa, privada e individual, deve-se, antes, a uma modificação na cultura medieval, até então monástica, para uma forma de ler escolástica, do que ao avanço tecnológico propriamente dito: o impresso.

As novas técnicas-pontuação, separação de palavras, normatização ortográfica e da letra, paginação-, além do codex, não surgiram a partir do impresso, mas sim a partir de uma nova forma de conceber o texto: o desenvolvimento da devoção e da espiritualidade ortodoxas como uma forma de comunicação mística com Deus. Dessa forma, segundo Manguel (1999), o modelo escolástico mostrou-se eficaz como forma de harmonizar diferentes opiniões em relação aos preceitos da fé religiosa e aos argumentos da razão humana. Esse método de leitura analítica 
consistia numa série de passos preordenados: primeiro, uma análise gramatical (lectio); depois, o sentido literal do texto (littera); o significado do texto segundo diferentes interpretações estabelecidas e, finalmente, a discussão de comentadores aprovados (sententia), de forma que os textos fossem sistemática e rigorosamente dissecados, não permitindo, assim, a interpretação fortuita pelos estudantes. Eram freqüentes as glosas e os comentários nas margens dos livros, além da compilação de textos clássicos. Nesse contexto, a figura do professor, particularmente dotado, sentado geralmente junto a um atril elevado, demonstrando o seu poder; é de fundamental importância.

Urge salientar, pois, que a transformação de uma prática de leitura monástica para uma prática escolástica não se deu subitamente, nem de forma regular e linear, em um único lugar e momento. Tanto Manguel (1999) quanto Saenger (1989), apesar de corroborarem o privilégio do oral na Antigüidade e Idade Média, afirmam, assim como Cavallo e Chartier (1998), a existência, desde a Antigüidade, de práticas de leitura visual e apontam o surgimento da separação das palavras por volta do século VII, antes da invenção da imprensa, além dos primeiros sinais de pontuação para facilitar ainda mais a tarefa do leitor silencioso. Consequientemente, esses fatos sinalizam a coexistência das duas práticas de leitura: a oral e a silenciosa. Manguel (1999: 67), por exemplo, afirma que

os primeiros regulamentos exigindo que os escribas ficassem em silêncio nos scriptoriuns dos conventos datam do século IX. Até então, haviam trabalhado com ditados ou lendo para si mesmos, em voz alta, o texto que estavam copiando.

Diante de tantas evidências, seria ingenuidade pensar que a invenção da imprensa, por si só, çonstituiu um marco para a 'derrocada' da leitura em voz alta e a 'supremacia' da leitura silenciosa e que as novas técnicas para facilitar a leitura advieram da revolução do impresso. Por outro lado, conforme afirma Manguel (1999), a invenção de Gutemberg trouxe vantagens: rapidez, uniformidade de textos e preço relativamente mais barato, além de acesso mais fácil aos livros. Se relegássemos esses dados, acabaríamos simplificando ou, até mesmo, camuflando a trajetória da história da leitura no mundo ocidental. 
Na mesma linha, Saenger (1989: 147-149) ressalta que, embora alguns especialistas considerem

o período medieval como uma prolongação da Antigüidade, impregnada da cultura do manuscrito e do oral, e a invenção da imprensa como o fator responsável pelo nascimento de uma cultura de comunicação silenciosa, [...] esse ponto de vista de uma comunicação essencialmente oral na Idade Média repousa sobre uma interpretação errônea da Antigüidade, feita pelos especialistas alemães no fin do século $X I X:$ que a prosa clássica teria sido composta segundo estruturas rítmicas, devendo, então, ser lida em voz alta.

Esses mesmos especialistas ainda se baseariam nas Confissões de Santo Agostinho, que confessa estranhar o hábito de Santo Ambrósio ler em silêncio e, também, na recomendação de Quintiliano da leitura em voz alta como método indispensável para a memorização. Saenger (1989) justifica-se, revelando que, já no século VII, surge a mais profunda mudança da escrita, com a aparição da separação das palavras, a qual irá fornecer o meio essencial de ler e copiar em silêncio os textos. Como exemplo, cita os primeiros traços da imposição da regra do silêncio nos scriptoriuns do século VII, nas Ilhas Britânicas e, no século XI, a cópia silenciosa como parte da vida monástica na França, apesar de ainda se ler oralmente.

Entretanto, é oportuno lembrarmos ao leitor que o objetivo deste trabalho é investigar e discutir se a leitura silenciosa teria suplantado a leitura oral no mundo contemporâneo. Ressalta-se que as questões já discutidas anteriormente, apesar de não serem o foco deste estudo, são fundamentais, uma vez que irão fornecer subsídios para fomentar uma maior reflexão sobre o tema em destaque. Salientamos, ainda, que não temos a pretensão de fazer generalizações, que exigiriam, no mínimo, uma metodologia de coleta de dados mais rigorosa, como, por exemplo, entrevistas e observação das aulas de leitura. Pretendemos, a partir de um pequeno corpus de informações, suscitar, nos leitores, o desejo por uma investigação mais aprofundada a respeito do assunto tratado. Para tanto, hipóteses e reflexões, fruto deste trabalho, poderão servir de orientação ou fonte de discussão para os futuros pesquisadores. 
Sendo assim, temos como proposta analisar a prática de leitura da escola do mundo contemporâneo, nos primeiros anos de escolarização, mais precisamente, de duas escolas da Rede Municipal de Belo Horizonte. Porém, anteriormente, convém salientar que alguns guias de leitura do final do século XIX e início do século XX constituem um forte indício de que a leitura oral era uma prática constante da escola daquela época, dado o fato de enfatizarem a necessidade e a importância de os professores centrarem mais forças na leitura silenciosa do que, propriamente, na leitura oral, justificando ser aquela uma prática necessária e mais eficaz para o desenvolvimento da compreensão. Esses guias constituem, assim, provas concretas para acreditarmos que, até o início do nosso século, pelo menos, ainda havia a prática de leitura oral em nossas escolas, pois serviam para instruir professores, principalmente, dos primeiros anos de escolarização. Um desses manuais é o de Pennell e Cusack (s.d.: 9193), que se refere à leitura silenciosa como "parte integrante da experiência universal diária". Segundo esses autores, "adultos e crianças leeem, quotidianamente, livros e revistas não com intuitos oratórios, mas com o fim de apropriar-se dos pensamentos e idéias neles fixados" e, por isso, acentuam "a necessidade de dedicar a escola maior espaço de tempo à leitura silenciosa do que à leitura oral".

Esses autores apoiam-se, por fim, em vários argumentos em defesa da prática de leitura silenciosa: economia de tempo, de esforço visual e vocal; auxílio na compreensão, haja vista a atenção se deter no sentido e não na articulação e enunciação das palavras; liberdade de escolha por parte do leitor; desenvolvimento individual de velocidade de leitura. Entretanto, eles sinalizam a necessidade de a escola também trabalhar com a leitura oral, embora aconselhem que devemos ter sempre em mente os perigos da leitura oral ou em voz alta, pois, em excesso, essa prática pode prejudicar a eficiência da leitura silenciosa, já que fixa e fomenta hábitos danosos de pronúncia e articulação lentas, prejudicando a reflexão e a rapidez. Oliveira (2001), em sua pesquisa, evidencia a distinção do processamento da compreensão na leitura em voz alta e silenciosa, destacando que a maior proficiência da compreensão viabilizada por essa prática deve-se a fatores relacionados com a natureza do processamento.

Embora Pennell e Cusack (s.d.) considerem a leitura silenciosa mais proveitosa, eficiente, eles apontam quatro vantagens da leitura em voz alta: compartilhar idéias; expressar com mais estilo e beleza certos tipos 
de material de leitura; fixar novos termos com mais facilidade; treinar a voz, educando-a.

Diante do já exposto, cabem-nos algumas indagações: será a leitura oral ou em voz alta uma prática do passado, da Antigüidade e da Idade Média, e a leitura silenciosa uma prática, por excelência, do mundo contemporâneo, pelo menos, no que se refere à prática de leitura da escola hoje? Como essa instituição vem trabalhando a leitura nos primeiros anos de escolarização do Ensino Fundamental? Que hipóteses podem corroborar ou justificar os resultados obtidos? Que concepção de lejtura permeia a prática de leitura da escola?

Essa investigação é fundamental não só por possibilitar desvelar a prática de leitura veiculada pela escola e a concepção que a sustenta, como também permite que profissionais da educação sirvam-se do resultado obtido, a partir da aplicação de um pequeno teste e das discussões por ele suscitadas. Com este trabalho, os professores poderão intervir melhor na formação de leitores, orientando-os mais adequadamente. Além disso, este estudo pode servir como referência para motivar futuras pesquisas.

\section{A concepção de leitura}

Antes de procedermos à análise das indagações já relacionadas, cabe-nos definir em que concepção de leitura nos amparamos. Ler, para nós, não pode ser entendido como simplesmente um ato estático e passivo do leitor de percorrer com os olhos o que está escrito, tampouco como um ato unilateral e solitário de transmissão de informações do emissor para o receptor. Ler não se esgota na decodificação pura da palavra escrita, isto é, não é um ato mecânico de decodificação de palavras, como se estas carregassem em si mesmas os significados. Para a compreensão de textos, o leitor não é um mero depositário de informações, assimilando tudo o que lhe é fornecido. Para compreendermos, não temos que memorizar e vocalizar as palavras, como se acreditava na Antigüidade e Idade Média, pois, nessa época,

o ensino era sobretudo oral: o mestre falava $e$ instruía e a criança ouvia e memorizava, pois saber ler era saber de cor. (...) o manuscrito continha uma escrita que se dirigia aos ouvidos e não aos olhos. (...) Era inconcebível ler sem apelar para o som da escrita (Barbosa, 1991: 98). 
Cavallo e Chartier (1998) comparam o ato de ler um texto literário, na Antigüidade e Idade Média, à execução de uma partitura musical, ou seja, ler com profundidade significava chegar ao cerne da expressão verbal. Entendia-se que o sentido do texto era colhido e, mesmo assim, só seria colhido, com segurança, por intermédio do ouvido, melhor do que pela vista. Acreditava-se, assim, que o sentido do texto era captado por meio das palavras, as quais, por si mesmas, carregavam as idéias. Cabia ao leitor decifrar as palavras.

Contrariamente, concebemos que a leitura envolve um engajamento de uma multiplicidade de processos cognitivos, de níveis de conhecimento _ o lingüístico, o textual, o conhecimento de mundo, o enciclopédico. Kleiman (1989: 13) afirma que "é mediante a interação de diversos níveis de conhecimento que o leitor consegue construir o sentido do texto. E porque o leitor utiliza justamente diversos níveis de conhecimento que interagem entre si, a leitura é considerada um processo interativo". Segundo essa autora, essa interação é possível através de processos bottom-up, do texto para o leitor, e de processos top-down, do leitor para o texto.

\section{Metodologia}

Para analisar as questões arroladas no final da introdução, tomamos como referência uma pequena amostra de alunos e professores de duas escolas municipais de Ensino Fundamental de Belo Horizonte do primeiro e segundo ciclo $\left(1^{\mathrm{a}}, 2^{\mathrm{a}}, 3^{\mathrm{a}}\right.$ e $4^{\mathrm{a}}$ séries $)$.

O teste envolveu 10 professoras, sendo 9 , professoras regentes do primeiro e segundo ciclo (1a $, 2^{\mathrm{a}}, 3^{\mathrm{a}}$ e $4^{\mathrm{a}}$ séries) da Escola Municipal Carlos Góis e 1 professora coordenadora das professoras do primeiro e segundo ciclo da Escola Municipal Aurélio Pires. Todas as professoras têm curso de magistério, mas a maior parte (70\%) já tem, atualmente, curso superior. Além das professoras, serviram, também, como sujeitos dessas duas escolas 24 alunos do sexo masculino e feminino do final do $2^{\circ}$ ciclo ( $4^{\mathrm{a}}$ série). Esses alunos compõem o corpus pela necessidade de se checar as respostas das professoras, confirmando-as ou não.

A Escola Municipal Carlos Góis compõe o quadro das 20 escolas da Regional Noroeste, situando-se na região noroeste de Belo Horizonte, no bairro Santo André, junto à favela Pedreira Prado Lopes. Os cursos 
oferecidos à comunidade local são Ensino Fundamental $\left(1^{\circ}\right.$ grau - $1^{\circ} \mathrm{e}$ $2^{\circ}$ ciclos ou pré-primário à $5^{\mathrm{a}}$ série), nos turnos manhã e tarde, e suplência de $1^{a}$ à $4^{\mathrm{a}}$ série, à noite. Essa escola atende a um total de 533 alunos.

Já a Escola Municipal Aurélio Pires integra o quadro das doze escolas da Regional Pampulha, situando-se mais na região norte de Belo Horizonte, no bairro Liberdade. Segundo informações da própria direção da escola, atende, atualmente, a 90\% de alunos de classe popular das vilas Santa Rosa, Santo Antônio e Santa Cruz. Os cursos oferecidos à comunidade local são Ensino Fundamental $\left(1^{\circ}, 2^{\circ}\right.$ e $3^{\circ}$ ciclos: pré-primário a $8^{a}$ série e Educação de Jovens e Adultos). Essa escola atende a cerca de 975 alunos.

O teste foi feito com professoras dessas duas escolas municipais de classes populares, para que pudéssemos ter um universo mais vasto, conferindo maior legitimidade, a fim de fazer certas generalizações, caso necessário, em termos de interpretação dos resultados e levantamento de algumas hipóteses. Dessa forma, esse pequeno teste poderá subsidiar melhor uma futura pesquisa referente a este assunto, que deu origem à questão investigada: a leitura em voz alta ou oral é uma prática que hoje não faz parte do universo da escola nos primeiros anos de escolarização do Ensino Fundamental?

Optou-se colher dados dos primeiros anos de escolarização $\left(1^{\mathrm{a}}, 2^{\mathrm{a}}\right.$ , $3^{\mathrm{a}}$ e $4^{\mathrm{a}}$ séries) do Ensino Fundamental pelo fato de suspeitarmos que, pelo menos, nessas primeiras séries, a prática de leitura em voz alta é, ainda, uma realidade.

Para checar essa suspeita, pedimos que os professores preenchessem o quadro a seguir, conforme fosse a sua realidade. Procurando garantir maior confiabilidade às respostas das professoras, também, perguntouse aos alunos da $4^{\mathrm{a}}$ série como eles costumavam ler em sala de aula. Veja Quadro 1:

No quadro a seguir, indique, colocando um $x$, como a leitura tem sido trabalhada de $1^{a}$ a $4^{a}$ série: 


\begin{tabular}{|c|c|c|c|c|c|c|c|c|c|}
\hline 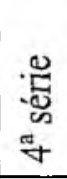 & 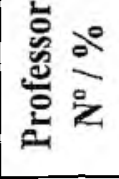 & & $m$ oे & & & & $-\stackrel{\circ}{\circ}$ & & 잉요 \\
\hline 芯 & 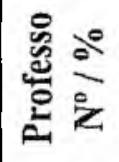 & - & & & & & $-\stackrel{\circ}{\circ}$ & & $\triangleq \stackrel{\circ}{\circ}$ \\
\hline 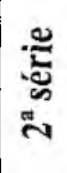 & 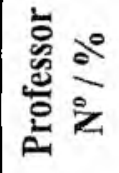 & 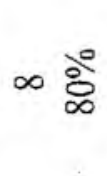 & v 亏ें & & & & & & $\cong \stackrel{\circ}{\circ}$ \\
\hline 芯 & 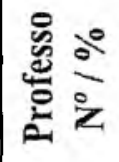 & 으 ᄋ్̊ㅇ & & & & & & & $\cong \stackrel{\check{\Xi}}{\varrho}$ \\
\hline & 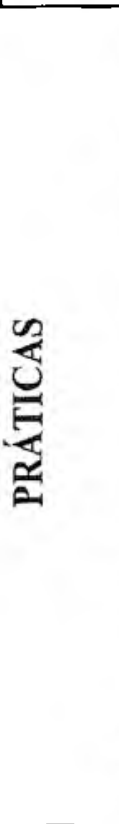 & 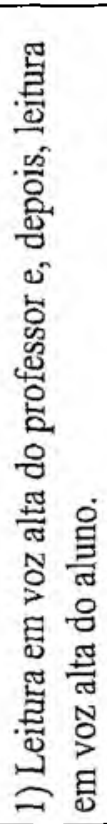 & 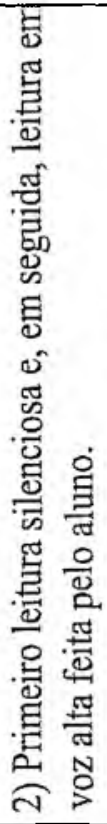 & 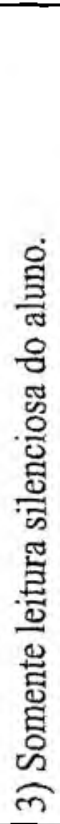 & 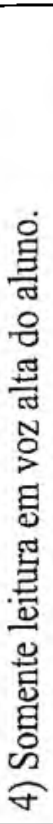 & 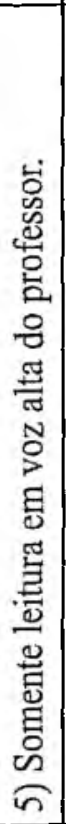 & 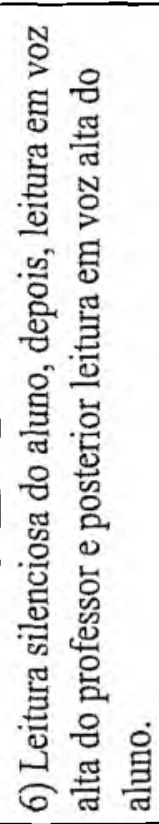 & 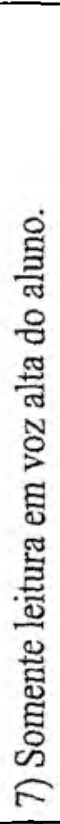 & $\frac{2}{0}$ \\
\hline
\end{tabular}

Coloque alguma observação, caso necessário. 
Acrescentou-se às informações prestadas uma consulta feita ao aluno. Pergunta dirigida aos alunos: em sala de aula, você lê os textos só silenciosamente, só em voz alta ou, primeiro, silenciosamente e, depois, em voz alta?

$\mathrm{Na}$ consulta feita às professoras, a suspeita de que, apesar de haver uma crença no imperialismo da leitura silenciosa no mundo ocidental, a leitura oral ou em voz alta ainda poderia ser uma prática comum, pelo menos, nos primeiros anos de escolarização é confirmada, conforme nos mostram os resultados do Quadro 1. Em todas as respostas, de uma forma ou de outra, a leitura em voz alta está presente nas atividades de sala de aula, seja ela feita, primeiramente, pelo professor e, depois, pelo aluno: $100 \%$ dos professores encaixam-se nesse quadro na $1^{\mathrm{a}}$ série, $80 \%$ na $2^{\mathrm{a}}$ série e $10 \%$ na $3^{a}$ série; seja a leitura em voz alta do aluno o último passo de um processo de leitura, que tem como primeiro passo a leitura silenciosa do aluno e, como segundo, a leitura em voz alta do professor: $70 \%$ dos professores encaixam-se nesse quadro na $3^{a}$ e $4^{a}$ séries; e seja, ainda, a leitura em voz alta feita pelo aluno, precedida de leitura silenciosa: $20 \%$ dos professores encaixam-se nesse quadro na $2^{a}$ série, $20 \%$ na $3^{a}$ série e $30 \%$ na $4^{a}$ série.

Ressalta-se, ainda, que, além de os alunos terem uma prática de leitura em voz alta nos primeiros anos de escolarização, essa leitura é, na maioria das vezes, monitorada pela leitura em voz alta do professor, feita previamente à leitura do aluno, haja vista os resultados do Quadro 1 confirmando que as práticas número 1 e 6 corroboram esse monitoramento: $100 \%$ dos professores na $1^{\mathrm{a}}$ série, $80 \%$ na $2^{\mathrm{a}}$ série e $10 \%$ na $3^{a}$ série (prática 1) e $70 \%$ dos professores na $3^{a}$ e $4^{a}$ séries (prática 6) contra apenas $20 \%$ dos professores que não fazem esse monitoramento na $2^{a}$ série, $20 \%$ na $3^{\mathrm{a}}$ série e $30 \%$ na $4^{\mathrm{a}}$ série (prática 2).

$\mathrm{Na}$ consulta feita aos 24 alunos da $4^{\mathrm{a}}$ série, com o objetivo de saber se a prática de leitura em voz alta é uma constante em sala de aula, 22 ou $91,7 \%$ apontaram a prática de leitura em voz alta precedida de leitura silenciosa, ao passo que apenas 2 ou $8,3 \%$ afirmaram só fazerem a leitura silenciosa. Ademais, três alunos dentre os 22 acrescentaram que, às vezes, fazem a leitura em voz alta em coro, guiados pelo professor. Mais uma vez, esse resultado corrobora a suspeita de que a prática de leitura oral ou em voz alta ainda é, hoje, uma prática presente, pelo menos, nos primeiros anos de escolarização. 
Diante dos resultados, ainda que incipientes, não podemos afirmar que a leitura oral ou em voz alta é uma prática do passado, da Antigüidade e da Idade Média, e que a leitura silenciosa, uma prática, por excelência, do mundo contemporâneo, no que diz respeito aos primeiros anos de escolarização do Ensino Fundamental. Da mesma forma, como houve um tempo, na Antigüidade e Idade Média, em que leitura silenciosa e em voz alta eram práticas que conviviam lado a lado, embora a prática oral se impusesse, parece ocorrer fato semelhante na Idade Contemporânea. Manguel (1999) cita, como exemplo, uma passagem das Confissões de Santo Agostinho, em que Agostinho narra a sensação de ler, silenciosamente, as Epístolas de Paulo com seu amigo, que as lia em voz alta. Constata-se, pois, que, atualmente, embora haja uma crença consensual na cultura do silêncio nos primeiros anos de escolarização do Ensino Fundamental, a prática escolar das duas instituições pesquisadas está mais voltada para uma leitura oralizada ou em voz alta, na maioria das vezes, monitorada pelas professoras.

Tendo em vista os resultados obtidos, relacionamos, neste trabalho, algumas justificativas que poderiam explicar o fato de a leitura oral ou em voz alta ainda ser, hoje, uma prática de leitura frequiente nos primeiros anos de escolarização do Ensino Fundamental.

Dentre essas justificativas, destacamos o fato de que a prática da leitura em voz alta nos primeiros anos de escolarização pode ser herança de uma pedagogia escolástica de leitura do século XVI, nas universidades e escolas de paróquias e mosteiros de toda a Europa. De acordo com Manguel (1999), o mérito de um leitor era muito mais recitar de cor e comparar interpretações reconhecidas e autorizadas, do que fazer uma leitura refletida e particular, uma vez que a compreensão não era o alvo do conhecimento.

A leitura dos textos era rigorosamente guiada pelo professor, que, sentado a um atril mais elevado, jamais os deixava à interpretação fortuita dos estudantes. Os textos eram dissecados, através de comentários ortodoxos, por meio dos quais se passavam os ensinamentos das virtudes e da moral cristã. Era uma leitura utilitária, cuja autoridade era o professor, quem deveria conduzir seus pupilos a uma leitura 'correta'. É comum ver nas iluminuras da época, o professor segurando uma vara de vidoeiro, o que também lhe confere extremo poder. Era comum, ainda, nesse tempo, a leitura em voz alta por quem encarnava o saber e detinha, assim, o poder, seguida, em silêncio, pelos alunos. 
Esse comportamento do professor ainda parece fazer parte do cotidiano escolar, pelo menos, nos primeiros anos de escolarização. É muito frequiente, também, a leitura ser guiada pelo professor, que passa ensinamentos e lições de moral, utilizando diversas práticas, mas, principalmente, estudos dirigidos, um dos instrumentos de controle. Outro instrumento de controle, também, muito presente nas salas de aulas são os livros didáticos, os quais funcionam como uma espécie de cartilha. A necessidade de maior controle no mundo contemporâneo parece ter aumentado à proporção em que ocorreu a 'democratização do ensino', a partir da década de 70, época em que houve um aumento do número de escolas para o povo e uma maior demanda de alfabetização. Fato semelhante ocorreu após a invenção da imprensa, uma vez que, devido às novas necessidades que se impunham em função da urbanização, também, houve uma crescente alfabetização, o que demandou um maior controle na leitura. Até a invenção da imprensa, a alfabetização era rara e o livro, propriedade de poucos.

Além disso, pode ser herança da Antigüidade e Idade Média o fato de que a leitura em voz alta serve como controle dos pensamentos do leitor, já que a leitura silenciosa pode, até certo ponto, ser 'perigosa', haja vista possibilitar uma leitura mais privada, deixando a mente 'ociosa', de forma que ofereça meios para expressar pensamentos questionadores. Cavallo e Chartier (1998) expõem os perigos da leitura silenciosa na Antiguiidade e Idade Média. Segundo esses autores, a intimidade da leitura silenciosa pode ter propiciado manifestações políticas subversivas e irônicas, na época, além de ser um dos fatores responsáveis pelo ressurgimento do gênero da literatura erótica.

Assim, também, Manguel (1999: 146) aponta a leitura oral como uma prática que submete e priva o leitor, sendo, pois, controladora:

Permitir que alguém pronuncie as palavras de uma página para nós é uma experiência muito menos pessoal do que segurar o livro e seguiro texto com nossos próprios olhos. Render-se à voz do leitor (...) retira nossa capacidade de estabelecer um certo ritmo para o livro, um tom, uma entonação que é exclusiva de cada um. $O$ ouvido é condenado à língua de outra pessoa, $e$ nesse ato estabelece-se uma hierarquia (d̀s vezes tornada aparente pela posição privilegiada do 
leitor, numa cadeira separada ou num pódio) que coloca o ouvinte nas mãos do leitor. Até fisicamente, o ouvinte seguirá aniúde o exemplo do leitor.

Em contrapartida, a leitura silenciosa permite que o leitor tenha mais liberdade para fazer uma leitura que é sua; que possa voltar a passagens já lidas; que possa ir e vir e parar em qualquer momento em que quiser; que dialogue com o texto de uma forma mais pessoal, livre; que tenha 'maus pensamentos'. Já a leitura em voz alta, comunitária, é uma forma de evitar o prazer pessoal, ao contrário da leitura silenciosa, que é individual. De acordo com Manguel (1999), a leitura silenciosa era uma prática perigosa, visto que fomentava o pecado da ociosidade, pois o leitor podia sonhar acordado, seguir seus próprios pensamentos, sem censura, podendo ir e vir no texto, além de parar onde bem entendesse. Essa leitura particular, reflexiva e não orientada poderia, pois, instigar os leitores a ter pensamentos fortuitos e pecaminosos.

Outra justificativa para o fato de a leitura oral ou em voz alta ainda ser hoje uma prática de leitura frequiente nos primeiros anos de escolarização do Ensino Fundamental pode estar calcada na concepção de leitura da Antigüidade e Idade Média: ler significava memorizar e, necessariamente, ter uma escrita que se dirigia aos ouvidos e não aos olhos. "Era inconcebível ler sem apelar para o som da escrita" (Barbosa, 1991: 98).

Assim, também, Cavallo e Chartier (1998: 8) afirmam que "no mundo antigo, na Idade Média, nos séculos XVI e XVII ainda, a leitura implícita mas também efetiva de numerosos textos é uma oralização, e seus 'leitores' são os ouvintes de uma voz leitora." Privilegiava-se, nessa época, o desenvolvimento da arte da oratória. A escrita tinha uma outra função, a de ser decifrada, e o leitor, a de ser o decifrador de textos.

Entretanto, passados vários séculos, a entonação, o ritmo, a fluência, a expressividade continuam sendo a tônica, pelo menos, nos primeiros anos do Ensino Fundamental, haja vista a presença marcante da prática de leitura em voz alta na sala de aula (Quadro 1), cujo foco não parece ser a compreensão. Essa parece ser uma etapa posterior à 'mecanização/ automatização' da leitura, entendida, pois, não como resultado da construção de sentido, na relação entre texto e leitor -concepção interativa de leitura. Portanto, há o pressuposto de que o leitor é uma tabula rasa e sua relação com o texto, passiva. O foco está no texto, o qual fornece 
todas as informações, cabendo ao leitor apenas apropriar-se delas. Essa concepção de leitura encontra suas raízes em fins da Idade Média, momento em que começa a se desenvolver uma outra prática de leitura: a escolástica. Um exemplo é citado por Olson (1997: 169): "[...] Lutero era positivista com respeito à interpretação. Acreditava que o sentido visado por um texto podia ser determinado com certeza e, conseqüentemente, que um texto só podia ser lido corretamente de um único modo".

Mas qual seria o problema com essa concepção de leitura não interativa? Um forte argumento a ser considerado é o foco dessa concepção apenas na força locucionária como condição para a compreensão de um enunciado falado ou escrito. Olson (1997) explora a teoria dos 'atos de fala'so (Austin, 1962) para mostrar como a leitura oral permite recuperar somente a força locucionária, desprezando a importância da força ilocucionária para uma comunicação eficiente. Para entendermos um enunciado, seja escrito ou falado, é fundamental que compreendamos o elemento ilocucionário. Se levarmos em consideração apenas aquilo que é dito (ato locucionário), não será possível preencher os 'vazios textuais', ou seja, fazermos inferências, desde as mais óbvias até as mais complexas. Olson (1997: 109) afirma que "a transcrição escrita só capta um aspecto privilegiado do enunciado, a saber, 'o que foi dito', e despreza o 'como entender'. Desprezar a força ilocucionária é conceber que as palavras, por si sós, são capazes de expressar todas as nuances envolvidas na construção do sentido: conhecimento enciclopédico e de mundo do leitor, o contexto, expectativas e objetivos desse leitor. No entanto, na construção do sentido do texto, estão envolvidos o engajamento de todos esses conhecimentos e habilidades, que não são determinados pelas palavras. Concordamos com Olson (1997: 111) quando afirma que

é preciso um esforço especial para perceber que a versão escrita não é uma representação completa das intenções de quem fala ou escreve. (...) A maioria dos leitores é atormentada pela

\footnotetext{
A teoria dos atos de fala traça uma distinção entre o ato locucionário (o que é dito ou assertado) e a força ilocucionária (como o falante queria que fosse entendido o que disse). Essa força ilocucionária não é lexicalizada e expressa sentimento, ordem, promessa etc.
} 
crença de que os textos significam exatamente o que dizem; acredita que a intenção comunicativa, que é inferida, está tão dada quanto a forma verbal. Os textos proporcionam uma representação do que foi dito, é verdade, mas não necessariamente do modo como quem falou desejava ser entendido.

Portanto, nas duas escolas onde foi coletado o pequeno corpus analisado, a concepção de leitura está antes para uma visão positivista do que para uma visão interativa de leitura, pelo menos, nos primeiros anos de escolarização. Um exemplo, cuja tônica é a expressividade, entonação, educação da voz, memorização na prática de leitura oral, é o próprio guia de leitura de Pennell e Cusack (s.d.: 127), em que há uma explicitação dos objetivos da leitura em voz alta. Dentre esses, destacamse a educação e o treino da voz, melhor fixação de termos novos (memorização) e a expressividade. Apesar de ser um guia do início do nosso século, constata-se que esses objetivos ainda são os mesmos, quando se faz hoje a leitura em voz alta em sala de aula.

Outro dado que parece corroborar a concepção de leitura como sinônimo de memorização foi a atitude das professoras entrevistadas no momento da seleção dos alunos que se submeteriam ao teste. As professoras aconselharam selecionar aqueles que tinham uma leitura corrente, ritmada, com mais expressividade. Em nenhum momento, colocaram em evidência aqueles que, apesar de não terem uma boa fluência na leitura, tinham uma boa compreensão, entendida, agora, como resultado da 'construção' do sentido pelo leitor, num processo dinâmico desse com o texto e o contexto.

\section{Conclusão}

Este trabalho suscita, além de possíveis questionamentos, uma pesquisa mais complexa, em que haja o controle de todas as variáveis e a implementação de uma metodologia adequada, cujo corpus seja composto, também, por entrevistas, observação das aulas de leitura, etc. Além disso, uma análise que abranja um número maior de sujeitos poderá garantir maior confiabilidade à pesquisa. É imprescindível, também, checar se as hipóteses/justificativas relacionadas neste trabalho, 
realmente, procedem, no que diz respeito às possíveis justificativas para o fato de a prática de leitura oral ser ainda uma realidade nos primeiros anos de escolarização do Ensino Fundamental.

Somente dessa forma, poderíamos verificar se, realmente, a leitura oral ou em voz alta é uma prática do passado, da Antigüidade e da Idade Média, e a leitura silenciosa, uma prática, por excelência, do mundo contemporâneo; como a escola vem trabalhando a leitura no Ensino Fundamental; que hipóteses podem corroborar ou justificar os resultados obtidos e, finalmente, em que concepção de leitura a prática dos professores está amparada.

Com este estudo, vimos, conforme resultados apresentados no Quadro 1, que as práticas mais utilizadas (1 e 6) são a leitura em voz alta do professor e a posterior leitura em voz alta do aluno. Possivelmente, o fato de o professor monitorar a leitura do aluno por meio de sua leitura, tanto mecânica quanto no que diz respeito ao sentido, através da inculcação de valores e pensamentos ortodoxos, pode ser uma herança da Antigüidade e Idade Média. Tanto essa hipótese quanto outras sugeridas ao longo deste trabalho merecem ser amplamente checadas. Não temos a pretensão de fazer generalizações, visto que quaisquer afirmações seriam ainda incipientes, em se tratando do pequeno corpus analisado.

Entretanto, os resultados apresentados, assim como algumas considerações e reflexões, certamente, poderão subsidiar investigações futuras. Este trabalho pode ser o primeiro passo na busca de conhecermos melhor as práticas de leitura que, mal ou bem, coexistem no mundo contemporâneo, principalmente, nos primeiros anos de escolarização em algumas escolas da Rede Municipal de Belo Horizonte. Ressalta-se, ainda, que este estudo é, também, uma pequena contribuição em relação a futuras pesquisas, a fim de que possamos, como professores, não só orientar melhor nossos alunos, entender em que concepção de leitura estamos amparados quando exercemos uma prática de leitura em sala de aula, como também compreender melhor a natureza de nossas práticas, muitas vezes, herdadas de épocas tão longínquas.

\section{Referências bibliográficas}

AUSTIN, J. L. How to do things with words. Cambridge, M.A.: Harvard University, 1962. 
BARBOSA, José Fulgêncio. Alfabetização e leitura. São Paulo: Cortez, 1991.

CAVALLO, G. CHARTIER, R. História da leitura no mundo ocidental. São Paulo: Ática, 1998.

KLEIMAN, Ângela. Texto e leitor: aspectos cognitivos da leitura. Campinas: Pontes, 1989.

MANGUEL, Alberto. Uma história da leitura. São Paulo: Companhia das Letras, 1999.

OLIVEIRA, Adriana C. Leitura silenciosa e em voz alta: dois processos distintos? Belo Horizonte: Faculdade de Letras da UFMG, 2001. (Dissertação, Mestrado em Letras: Estudos Linguíísticos).

OLSON, David R. O mundo no papel. As implicações conceituais e cognitivas da leitura e da escrita. São Paulo: Ática, 1997.

SAENGER, Paul. Manières de lire médiévales. In: CHARTIER, Roger, MARTIN, Henri-Jean. Histoire de l'édition française: le livre conquérant. Paris: Fayar d/ cercle de la librairie, 1989. p. 147-161. 